УДК 355.40:004.82(477)

Сергій Станіславович Гаценко (кандидат технічних наук)

Олег Володимирович Костенко

Віктор Петрович Кузьменко

Василь Михайлович Мазуренко

Національний університет оборони Украӥни імені Івана Черняховського, Київ, Украӥна

\title{
МЕТОДИКА РАНЖУВАННЯ ДЖЕРЕЛ РОЗВІДУВАЛЬНИХ ВІДОМОСТЕЙ РАДІОЕЛЕКТРОННОЇ РОЗВІДКИ ПРИ ОРГАНІЗАЦІЇ І ВЕДЕННІ РОЗВІДКИ
}

В статті пропонується вирішення актуального наукового завдання розробки науковометодичного апарату ранжування джерел розвідувальних відомостей, які характеризують об'єкти розвідки при оцінці оперативної обстановки та радіоелектронної обстановки в інтересах планування розвідки. Ранг джерела розвідувальних відомостей розраховується з урахуванням його якісних $i$ кількісних характеристик. Функиіонування залежності рангу джерела розвідувальних відомостей від його розвідувальної цінності $i$ ототожнюємих з ними радіоелектронною обстановкою реалізується нечіткою нейронною мережею. Результатом виконання процедури ранжування є введення на множині джерел розвідувальних відомостей щзо плануються, відношення порядку. Впорядкування множини джерел розвідувальних відомостей дозволяє формалізувати $і$ вирішити завдання квазіоптимального розподілу засобів і сил розвідки.

Ключові слова: ранжування, джерела розвідувальних відомостей, об'єкт розвідки, планування розвідки, нечіткі множини, застосування сил і засобів розвідки.

\section{Вступ}

Результативність процесу функціонування сил і засобів розвідки визначається кількістю викритих об'єктів розвідки (ОР) через викриття функціонування радіоелектронних засобів (РЕ3), радіотехнічних систем (РТС), які $\epsilon$ джерелами розвідувальних відомостей (ДРВ) і якістю добутої про них розвідувальної інформації.

В свою чергу вказані показники залежать від ступеня відповідності результатів вирішення завдання планування застосування сил і засобів розвідки (Сі3Р), у відповідності до умов радіоелектронної обстановки (РЕО).

Ключовою операцією, яка використовується при вирішенні завдання планування бойового застосування засобів розвідки $€$ операція виявлення та розпізнавання ДРВ.

ДРВ, які виявляються засобами розвідки, характеризуються множиною якісних и кількісних характеристик, маючих різну розвідувальну цінність і відповідно с цим різну ступінь важливості.

Таким чином, виявлення та розпізнавання ДРВ потребує реалізації достовірного, науково обгрунтованого відображення множини характеристик ДРВ Н, на множині дійсних чисел, які характеризують ранг $k$-го ДРВ $\mathrm{w}_{\mathrm{k}}: \mathrm{f}\left(\mathrm{h}_{\mathrm{k}}\right) \rightarrow \mathrm{w}_{\mathrm{k}}$ де $\mathrm{h}_{\mathrm{k}}=\left\{\mathrm{h}_{1}, \ldots, \mathrm{h}_{\mathrm{n}}\right\}, \mathrm{h}_{\mathrm{i}} \in \mathrm{H}$.

Представлення відображення $\mathrm{f}\left(\mathrm{h}_{\mathrm{k}}\right) \rightarrow \mathrm{w}_{\mathrm{k}} \quad$ в аналітичному вигляді в контексті завдання що розглядається на сьогоднішній день не існує. Методики які $\epsilon$ на теперішній час реалізують відображення $\mathrm{f}\left(\mathrm{h}_{\mathrm{k}}\right) \rightarrow \mathrm{w}_{\mathrm{k}} \quad 3 \quad$ використанням математичного апарату на основі методів експертних оцінок, методу нормування, або методів мультиплікативної (адитивної) згортки. Застосування вказаної групи методів для реалізації процедури ранжування ДРВ обумовлюється наявністю в існуючій методиці планування застосування сил і засобів розвідки наступних недоліків:

відсутність автоматизації процедури планування застосування засобів розвідки в заданих умовах РЕО;

аналіз результатів виконання плану застосування сил i засобів розвідки не формалізований і носить суб'єктивний характер;

облік наслідків результатів застосування засобів розвідки в ході виконання наступного планування застосування сил i засобів розвідки відсутній.

Таким чином, в умовах, коли кількість множини ранжуємих ДРВ має велику кількість, існуючий підхід ранжування ДРВ не дозволяє реалізувати адаптивне раціональне планування застосування засобів розвідки.

Постановка проблеми. Декомпозиція завдання планування застосування сил і засобів розвідки на ряд часткових завдань i взаємозв'язок представлені на рис. 1.

В формалізованому вигляді завдання ранжування ДРВ в контексті вирішення завдань планування застосування Сі3Р, може бути представлена в наступному вигляді: 


$$
\mathrm{r}^{*}=\underset{\pi \in \mathrm{G}}{\arg \max }(\mathrm{F}(\pi[\mathrm{a}, \mathrm{r}])),
$$

де: $\mathrm{F}(\pi[\mathrm{a}, \mathrm{r}])$ - цільова функція показника ефективності функціонування Сi3Р;

$(\pi[\mathrm{a}, \mathrm{r}]) \quad$ - план РЕР при використанні відповідного алгоритму планування а до ранжуемого списку ДРВ r ; a - алгоритм планування застосування Сi3Р;

$\mathrm{r}$ - ранжований список ДРВ, який складається iз $\mathrm{n}$ елементів, значення $i$-го елемента $\mathrm{r}$ характерує ранг $i$-го ОР серед $\mathrm{n}$ джерел;

$\mathrm{G}$ - множина обмежень які накладаються на процедуру планування в заданих умовах РЕО.

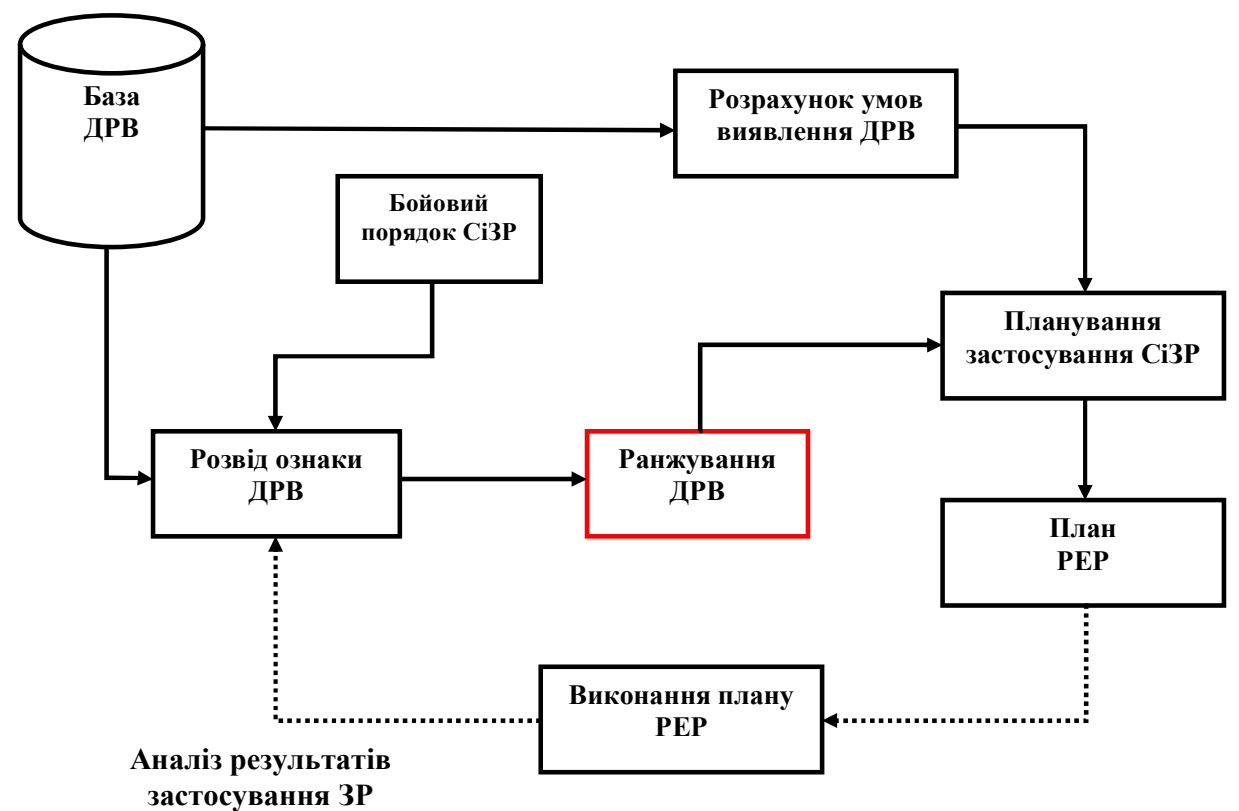

Рис. 1. Структурно-логічна схема вирішення завдання планування застосування СіЗР

В якості значення цільової функції $\mathrm{F}(\pi[\mathrm{a}, \mathrm{r}])$ виразу (1) в даній роботі розглянемо сумарний ранг ДРВ, в ході виконання плану $\pi$. Результативність процесу виконання плану РЕР $\pi$ пропонується оцінити згідно наступного критерію.

$$
\left(\frac{\sum_{\mathrm{i}=1}^{\mathrm{n}} \mathrm{k}_{\mathrm{i}} \cdot \mathrm{r}_{\mathrm{i}}}{\mathrm{n}}\right) \rightarrow \min ;
$$

$$
\left\{\begin{array}{l}
\mathrm{k}_{\mathrm{i}}=0, \text { якщо - й ОР не врахований; } \\
\mathrm{k}_{\mathrm{i}}=1, \text { якщоі - й ОР врахований. }
\end{array}\right.
$$

де $\mathrm{k}_{\mathrm{i}}$ - бінарний коефіцієнт, який характеризує факт врахування і ДРВ в ході виконання плану $\pi$;

$\mathrm{r}_{\mathrm{i}}-$ ранг $\mathrm{i}$-го ДРВ розрахований по запропонованій методиці;

$\mathrm{n}$ - кількість ДРВ які враховуються при плануванні.

Аналіз останніх досліджень і публікацій. В $[1,2]$ автором запропонована методика визначення раціональної кількості розвідувальних ознак для визначення приналежності їх до об'єктів розвідки. Авторами робіт [3-5] було запропоновано науковометодичний апарат визначення стану об'єктів розвідки. Запропоновані підходи вимагають значних, потужних обчислювальних ресурсів. Аналіз робіт [6-8] стверджує, що завдання оцінки рангу ДРВ подібна класичній задачі класифікації (розпізнавання) образів. Найбільш поширеним i апробованим математичним апаратом, застосовуваним для вирішення подібних завдань на сьогоднішній день, $€$ математичних апарат нейронних мереж. Разом 3 тим застосування класичної нейронної мережі для вирішення завдання ранжування значної кількості ДРВ пов'язане 3 проблемою навчання нейронних мереж і передбачає наявність певної навчальної вибірки. Відповідно, для реалізації даної процедури потрібно множина $\mathrm{R}$, що включає в якості своїх елементів пари значень i безліч характеристик. Процес формування безлічі $\mathrm{R} 3$ обов'язковим виконанням умови узгодженості даних - складна, трудомістка процедура, що викликано неможливістю охарактеризувати складний багатокритерійний об'єкт однієї чисельною величиною. Достовірне рішення даного завдання можна забезпечити, запропонувавши характеризувати ДРВ як джерело, здатне належати до трьох класів - “важливе”, “середнє”, “неважливе” - 3 певною функцією належності до кожного класу. Формалізацію даної процедури зручно проводити, за допомогою математичного апарату теорії нечітких множин [9, 10].

Таким чином метою статті $\epsilon$ розробка методики ранжування ДРВ радіоелектронної розвідки при організації та веденні розвідки 3 використанням математичного апарату нечітких штучних нейронних мереж $[11,12]$, що дозволить враховувати наслідки застосування засобів розвідки для спостереження за ДРВ в ході планування розвідки 3 застосуванням принципів ранжування ДРВ з врахуванням динамічних змін PEO. 


\section{Виклад основного матеріалу дослідження}

Методика ранжування ДРВ $з$ використанням нечіткої нейронної мережі складається в послідовного виконання наступних кроків.

Крок 1. Формується архітектура нейронної мережі, у вигляді графа $\mathrm{G}=(\mathrm{X}, \mathrm{V})$, де $\mathrm{X}$ множина вершин нейронної мережі, V - множина зв'язків між елементами множини $X$. Ваги зв'язків $\mathrm{w}_{\mathrm{ij}}$ між нейронами мережі ініціалізуються випадковими значеннями в інтервалі можливих значень від $-0,5$ до 0,5 . Розраховується значення коефіцієнта $\mathrm{w}_{\mathrm{ij}}^{*}$ :

$$
\mathrm{w}_{\mathrm{ij}}^{*}=\sqrt{\sum_{\mathrm{j}=1}^{\mathrm{n}} \mathrm{w}_{\mathrm{ij}}^{2}}
$$

де $\mathrm{n}$ - кількість вершин в i-му шарі нечіткої нейронної мережі.

Здійснюється переініціалізація ваг зв'язків між нейронами суміжних шарів:

$$
\mathrm{w}_{\mathrm{ij}}=\frac{\beta \cdot \mathrm{w}_{\mathrm{ij}}}{\mathrm{w}_{\mathrm{ij}}^{*}},
$$

де $\beta-$ фактор масштабування, який розраховується згідно виразу

$$
\beta=0,7 \cdot p^{\frac{1}{n}},
$$

де $\mathrm{p}$ - кількість нейронів, у внутрішніх шарах нейронної мережі;

n - кількість нейронів шару.

Для кожної вершини нейронної мережі випадковим шляхом встановлється величина зміщення $\mathrm{w}_{0 \mathrm{j}}, \mathrm{w}_{0 \mathrm{j}} \in[-\beta, \beta]$.

Крок 2. На вхід нейронної мережі подаються об'єкти вибірки, що навчається - вектор $\mathrm{x}=\left(\mathrm{x}_{1}, \mathrm{x}_{2}, \mathrm{x}_{3}, \mathrm{x}_{4}, \mathrm{x}_{5}, \mathrm{x}_{6}\right)$, а також відповідні еталони результатів їх обробки по приналежності до класів множини $\mathrm{C}$ - вектора $\mathrm{d}$.

Крок 3. Виконання процедури фазифікації першого шару нейронної мережі. Дана процедура полягає у визначенні функції належності $\mu\left(\mathrm{x} \mid \mathrm{c}_{\mathrm{j}}\right)$. характеристик ДРВ $\mathrm{x}_{1}, \mathrm{x}_{2}, \mathrm{x}_{3}, \mathrm{x}_{4}, \mathrm{x}_{5}$, до класів, визначених на множині $\mathrm{C}-\mu\left(\mathrm{x} \mid \mathrm{c}_{\mathrm{j}}\right), \mathrm{j} \in \overline{1,}|\mathrm{C}|_{5}$.

Під функцією належності нечіткої множини розуміють узагальнену індикаторну функцію класичної множини. Реалізація даної процедури включає два етапи.

Перший етап - розрахунок центрів класів $\mathrm{V}_{\mathrm{ij}}$ елементів множини С для кожної розвідувальної ознаки ДРВ.

$$
\begin{aligned}
& \mathrm{V}_{\mathrm{ij}}^{\mathrm{S}}=\frac{\sum_{\mathrm{x} \in \mathrm{X}_{\mathrm{i}}\left(\mu^{\mathrm{S}}\left(\mathrm{x} \mid \mathrm{c}_{\mathrm{j}}\right)\right)^{2} \cdot \mathrm{x}}}{\sum_{\mathrm{x} \in \mathrm{X}_{\mathrm{i}}}\left(\mu \mathrm{S}\left(\mathrm{x} \mid \mathrm{c}_{\mathrm{j}}\right)\right)^{2}}, \\
& \sum_{\mathrm{x} \in \mathrm{X}_{\mathrm{i}}}\left(\mu \mathrm{S}\left(\mathrm{x} \mid \mathrm{c}_{\mathrm{j}}\right)\right)^{2} \neq 0,
\end{aligned}
$$

де $\mathrm{S}$ - номер ітерації;

$\mathrm{X}_{\mathrm{i}}$ - множина джерел вибірки що навчається, яка характеризує функцію належності значень і - й характеристики ДРВ до елементів множини С .

Другий етап полягає у розрахунку значень фукції приналежності $i$-й характеристики ДРВ на S -й ітерації:

$$
\begin{gathered}
\mu^{S}\left(\mathrm{x} \mid \mathrm{c}_{\mathrm{j}}\right)=\frac{1 /\left(\mathrm{x}-\mathrm{V}_{\mathrm{ij}}\right)^{2}}{\sum_{\mathrm{j}=1}^{|\mathrm{C}|}\left(1 /\left(\mathrm{x}-\mathrm{V}_{\mathrm{ij}}\right)^{2}\right)}, \\
\mu^{\mathrm{S}}\left(\mathrm{x} \mid \mathrm{c}_{\mathrm{j}}\right)=1, \text { якщо }\left(\mathrm{x}-\mathrm{V}_{\mathrm{ij}}\right)^{2}=0 .
\end{gathered}
$$

Обидва етапи виконуються ітераційно до тих пір, доки різниця отриманих значень центрів класів не буде відповідати умові

$$
\left|\mathrm{V}_{\mathrm{ij}}^{\mathrm{S}}-\mathrm{V}_{\mathrm{ij}}^{\mathrm{S}-1}\right| \leq \varepsilon,
$$

де $\varepsilon$ - мінімально можлива різниця значень центрів класів, отриманих на двох послідовних ітераціях.

Вираз (7) дозволяє визначити функцію належності характеристик ДРВ до елементів множини С в залежності від іiї кількісного значення.

Результатом проходження вектора характеристик ДРВ х через перший шар мережі є синтез другого шару мережі, активаційна функція вершин якого має вид

$$
\mathrm{y}_{2 \mathrm{k}}=\min \left(\mu\left(\mathrm{x} \mid \mathrm{c}_{\mathrm{j}}\right)\right), \mathrm{i} \in \overline{1,6}, \mathrm{j} \in \overline{1,3},
$$

де $\mu\left(\mathrm{x}_{\mathrm{i}}\right)$ - функція належності $i$-й характеристики яка використовується в процесі навчання джерела, вибірки що навчає до $\mathrm{j}$ - го елементу множини С.

Аргумент виразу (8) визначається значеннями сигналів, які розповсюджуються вершинамибатьками вершини $\mathrm{k}$ графа нечіткої множини $\mathrm{C}$.

Крок 4. Кожний нейрон третього і наступного шарів мережі отримують сигнал від усіх нейронів попереднього шару, перетворюючі отриманий сигнал у відповідності з активаційною функцією і транслюється кожному нейрону наступного шару.

Аргумент активації функції нейрона $z_{j}$ розраховується згідно виразу

$$
\mathrm{z}_{\mathrm{j}}=\mathrm{w}_{0 \mathrm{j}}+\sum_{\mathrm{i}=1}^{\mathrm{n}} \mathrm{y}_{\mathrm{i}} \cdot \mathrm{w}_{\mathrm{ij}},
$$

де $\mathrm{n}$ - кількість нейронів в попередньому шарі.

На основі отриманого значення аргументу $z_{j}$ розраховуємо значення активаційної функції нейрону $\mathrm{y}_{\mathrm{j}}=\mathrm{f}\left(\mathrm{z}_{\mathrm{j}}\right)$.

Крок 5. Проводиться перевірка вимог продовження навчання нейронної мережі згідно визначеному критерію. Якщо критерій зупинки виконується, потік управління алгоритмом передається на крок 9. Помилка роботи класифікатора вираховується на останньому шарі нейронної мережі згідно виразу: 


$$
\varepsilon=\sum_{\mathrm{i}=1}^{\mathrm{n}}\left|\mathrm{d}_{\mathrm{i}}-\mathrm{y}_{\mathrm{i}}\right|
$$

Крок 6. Виконується зворотне розповсюдження помилки. Кожен нейрон вихідного шару отримує цільове значення $\mathrm{d}_{\mathrm{i}}$ обчислює величину похибки $\sigma_{\mathrm{i}}$ :

$$
\sigma_{i}=\left(d_{i}-y_{i}\right) \cdot f^{\prime}\left(z_{i}\right),
$$

де $\mathrm{f}^{\prime}\left(z_{\mathrm{i}}\right)=\mathrm{f}^{\prime}\left(\mathrm{z}_{\mathrm{i}}\right) \cdot\left(1-\mathrm{f}\left(\mathrm{z}_{\mathrm{i}}\right)\right)$.

Розраховується величина коректування вісі зв'язку $\Delta \mathrm{w}_{\mathrm{ji}}$, а також величини коректування зміщення $\Delta \mathrm{w}_{0 \mathrm{j}}$ :

$$
\Delta \mathrm{w}_{\mathrm{ji}}=\alpha \cdot \sigma_{\mathrm{i}} \cdot \mathrm{z}_{\mathrm{j}} ; \Delta \mathrm{w}_{0 \mathrm{i}}=\alpha \cdot \sigma_{\mathrm{i}} .
$$

Величина $\sigma_{i}$ відправляється нейронам попереднього шару.

Крок 7. Кожний нейрон внутрішнього шару сумує вхідні від нейронів в наступному шарі помилки $\sigma_{i}$ i вираховує величину помилки, помножуючи отримане значення на похідну активуючої функції.

$$
\sigma_{i}=f^{\prime}\left(z_{i}\right) \cdot \sum_{j=1}^{n} \sigma_{j} \cdot w_{i j} .
$$

Обчислюючи зміни вагів зв'язків між нейронами суміжних зв'язків згідно виразу:

$$
\Delta \mathrm{w}_{\mathrm{ji}}=\alpha \cdot \sigma_{\mathrm{i}} \cdot \mathrm{z}_{\mathrm{j}} ; \Delta \mathrm{w}_{0 \mathrm{i}}=\alpha \cdot \sigma_{\mathrm{i}} .
$$

Крок 8. Кожен нейрон змінює ваги своїх зв'язків 3 елементами зміщення i нейронами попереднього шару:

$$
\mathrm{w}_{\mathrm{ji}}=\mathrm{w}_{\mathrm{ji}}+\Delta \mathrm{w}_{\mathrm{ji}} \cdot \mathrm{i} \cdot
$$

Крок 9. Кінцевий ранг ОР за допомогою виразу

$$
\mathrm{r}_{\mathrm{i}}=\left|\begin{array}{llll}
\mathrm{y}_{1} & \mathrm{y}_{2} & \ldots & \mathrm{y}_{\mathrm{n}}
\end{array}\right| \times\left|\mathrm{c}_{1} \mathrm{c}_{2} \quad \ldots \mathrm{c}_{\mathrm{n}}\right|^{\mathrm{T}},
$$

де $c_{i}$ - коефіцієнти які характеризують кількісну міру відповідних характеристик множини C .

Приклад реалізації методики. Автоматизація процесу ранжування ДРВ виконана шляхом використання програмного забезпечення, який реалізує розроблену методику. Фрагмент даних, який визначає функції належності аргументів нечіткої мережі до елементів множини С , наведено в табл. 1.

Таблиця 1

\begin{tabular}{|c|c|c|c|c|c|c|c|c|c|c|c|}
\hline$x_{1}$ & $\mu_{1}$ & $\mu_{2}$ & $\mu_{3}$ & $x_{2}$ & $\mu_{1}$ & $\mu_{2}$ & $\mu_{3}$ & $x_{3}$ & $\mu_{1}$ & $\mu_{2}$ & $\mu_{3}$ \\
\hline 10,00 & 0,92 & 0,06 & 0,02 & 1,80 & 0,00 & 0,11 & 0,89 & 0 & 0,00 & 0,04 & 0,96 \\
\hline 50,00 & 0,80 & 0,15 & 0,05 & 2,13 & 0,01 & 0,11 & 0,88 & 9 & 0,03 & 0,05 & 0,95 \\
\hline 100,0 & 0,70 & 0,22 & 0,08 & 2,46 & 0,02 & 0,10 & 0,88 & 18 & 0,15 & 0,10 & 0,75 \\
\hline 122,1 & 0,68 & 0,23 & 0,09 & 2,79 & 0,04 & 0,10 & 0,86 & 27 & 0,15 & 0,31 & 0,54 \\
\hline$x_{4}$ & $\mu_{1}$ & $\mu_{2}$ & $\mu_{3}$ & $x_{5}$ & $\mu_{1}$ & $\mu_{2}$ & $\mu_{3}$ & $x_{6}$ & $\mu_{1}$ & $\mu_{2}$ & $\mu_{3}$ \\
\hline 700 & 0,01 & 0,10 & 0,89 & 0,9 & 0,01 & 0,09 & 0,90 & 7,0 & 0,01 & 0,10 & 0,89 \\
\hline 600 & 0,02 & 0,13 & 0,85 & 0,8 & 0,10 & 0,25 & 0,65 & 7,4 & 0,02 & 0,13 & 0,85 \\
\hline 500 & 0,03 & 0,17 & 0,80 & 0,7 & 0,15 & 0,33 & 0,52 & 7,8 & 0,03 & 0,17 & 0,80 \\
\hline 450 & 0,04 & 0,22 & 0,74 & 0,6 & 0,21 & 0,54 & 0,25 & 8,2 & 0,04 & 0,22 & 0,74 \\
\hline
\end{tabular}

В табл. 1 кожна характеристика ДРВ визначається четвіркою значень $\mu_{1}, \mu_{2}, \mu_{3}, \mu_{4}$. Де $\mathrm{x}$-величина характеристики, $\mu_{1}$ - функція належності величини х до і джерела множини. Навчаєма вибірка нейронної мережі визначена на

Фрагмент навчаємої вибірки нечіткої нейронної мережі

\begin{tabular}{|c|c|c|c|c|c|c|c|c|}
\hline$x_{1}$ & $x_{2}$ & $x_{3}$ & $x_{4}$ & $x_{5}$ & $x_{6}$ & $\mu_{1}$ & $\mu_{2}$ & $\mu_{3}$ \\
\hline 600 & 1,8 & 0 & 200 & 0,85 & 7,0 & 0,01 & 0,10 & 0,89 \\
\hline 600 & 1,8 & 10 & 200 & 0,85 & 7,0 & 0,01 & 0,24 & 0,75 \\
\hline 600 & 3,0 & 0 & 200 & 0,85 & 7,0 & 0,01 & 0,24 & 0,75 \\
\hline 600 & 1,8 & 0 & 200 & 0,65 & 7,0 & 0,1 & 0,3 & 0,6 \\
\hline 600 & 1,8 & 0 & 200 & 0,85 & 11,0 & 0,01 & 0,20 & 0,79 \\
\hline 600 & 1,8 & 0 & 300 & 0,85 & 7,0 & 0,01 & 0,35 & 0,64 \\
\hline 300 & 1,8 & 0 & 200 & 0,85 & 7,0 & 0,01 & 0,10 & 0,89 \\
\hline
\end{tabular}
$\mathrm{o}=\left(\mathrm{x}_{1}, \mathrm{x}_{2}, \mathrm{x}_{3}, \mathrm{x}_{4}, \mathrm{x}_{5}, \mathrm{x}_{6}, \mathrm{c}_{1}, \mathrm{c}_{2}, \mathrm{c}_{3}\right)$.

Фрагмент навчаємої вибірки нечіткої нейронної мережі наведений в табл. 2.

Таблиця 2 
На основі аналізу розрахованих вище даних, можемо зробити висновок про те що, використання нечіткої нейронної мережі дозволяє реалізувати відображення $\mathrm{f}\left(\mathrm{h}_{\mathrm{k}}\right) \rightarrow \mathrm{w}_{\mathrm{k}}$ з високим ступенем достовірності одержаних результатів середнеквадратична помилка навчання нейронної мережі складає 3,9 пункта рагу ДРВ.

Таким чином, результати запронованої методики, $\epsilon$ достовірними i можуть бути використані в ході вирішення завдання планування спостереженя за ДРВ.

\section{Висновки й перспективи подальших досліджень}

Таким чином, розроблена методика враховує в роботі ранжування ДРВ, що виконуються в рамках планування застосування засобів розвідки, фактори, впливаючі на умови викриття ДРВ і РЕО.

Використання математичного апарату нечітких штучних нейронних мереж дозволяє враховувати

\section{Лimepamypa}

1. Гаценко С. С. Методика раціонального розподілу розвідувальної інформації за важливістю та кількістю розвідувальних ознак в умовах невизначеності: Збірник наукових праць НДІ ГУР Міністерства оборони України, 2017. № 43. С. 111-120. 2. Гаценко С. С. Інформаційна система оцінювання оперативної обстановки в умовах невизначеності: К.: НУОУ, 2017. № № 1 (140), С. 157-165. 3. Шуренок В. А. Методика оцінки космічної обстановки на базі нечіткої логіки: Збірник наукових праць Військового інституту Київського національного університету імені Тараса Шевченка. 2003. С. 191-203. 4. Гребенюк О. П. Застосування системно-когнітивного аналізу для автоматизації управління системою радіомоніторингу / О. П. Гребенюк, М. А. Роговець, В. А. Шуренок // Вісник ЖДТУ / Технічні науки. - 2010. - № 1 (52). - С. 72 - 80. 5. Шуренок В.А., Дзюбчук Р.В., Роговець М.А. Інформаційна система підтримки прийняття рішення оцінювання радіоелектронної обстановки на командних пунктах частин та підрозділів особливого призначення в умовах невизначеності на основі концепції „м'яких обчислень". Труди академії. - Київ: Національна Академія оборони України. 2006, № 71. с. 50-58. 6.Тэрано Т., Аса и К.. Сугено М. Прикладные нечеткие системы. - М.: Мир,1993. -368 с. 7. Гилл Ф., Мюррей У.. наслідки застосування засобів розвідки для спостереження за ОР через функціонування ДРВ в ході планування розвідки, застосовувати принципи ранжування ДРВ під умови РЕО, динмічно змінються.

Запропонована методика реалізовує комплексний підхід до вирішення завдання ранжування ДРВ, та забезпечує доягнення потрібного ступеня результативності процесу функціонування системи РЕР в різних умовах PEO.

Напрямками подальших досліджень, 3 врахуванням проведеного в рамках дослідженя експеременту бачиться, в можливості іiі інтеграції в існуюче розвідувально-інформаційне забезпечення, для підвищення оперативності планування збору і обробку розвідувальної інформації про ОР та ДРВ.

Райт М. Практическая оптимизация: мер. с англ. - М.: Мир, 1985. 509 с. 8. Круглов В.В.. Борисов В.В. Искусственные нейронные сети. Теория и практика. - М Горячая линия - Телеком, 2002. - 382 с. 9.Пермяков О. Ю. Теоретические основы обработки нечетких данных в аналитических задачах специального математического обеспечения: Дисс. на соис. уч. степени д. т. н. К.: 1995. 198 с. 10. Гаценко С. С. Зуйко В. В., Зотов С. В. Методика вироблення та надання рекомендацій в умовах невизначеності та суперечливості розвідувальної інформації: Збірник наукових праць ЦНДІ ОВТ ЗСУ. 2016. №3(62). С. 12-23. 11. Method of integral estimation of channel state in the multiantenna radio communication systems $\mathrm{S}$. Kalantaievska. H. Pievtsov, A. Kuvshynov, S. Hatsenko, A. Shyshatskyi, S. Yarosh, S. Zubrytskyi, R. Zhyvotovskyl, S. Petruk, V. Zulko Eastern-european journal of enterprise technologies. Vol. 5, No 9 (95) pp. 60-76, 2018: Information and controlling system. 12. Method of Immunity Minimization of the Free Platform ed Inertial Navigation System of Unmanned Aircrafts R. Bieliakov, S. Hatsenko, O. Fesenko, R. Zhyvotovskyi, S. Petruk, 2nd Ukraine Conference on Electrical and Computer Engineering Lviv, Ukraine, July 2-6, pp. 803-808, 2019.

\title{
МЕТОДИКА РАНЖУВАННЯ ДЖЕРЕЛ РОЗВІДУВАЛЬНИХ ВІДОМОСТЕЙ РАДІОЕЛЕКТРОННОЇ РОЗВІДКИ ПРИ ОРГАНІЗАЦІЇ І ВЕДЕННІ РОЗВІДКИ
}

\author{
Сергей Станиславович Гаценко (кандидат технических наук) \\ Олег Владимирович Костенко \\ Виктор Петрович Кузьменко \\ Василий Михайлович Мазуренко
}

\section{Национальный университет обороны Украины имени Ивана Черняховского, Киев, Украина}

В статье предлагается решение актуальной научной задачи разработки научно-методического аппарата ранжирование источников разведьвательных сведений, характеризующих объекты разведки при оценке оперативной обстановки и радиоэлектронной обстановки в интересах планирования разведки. Ранг источники разведывательных сведений рассчитывается с учетом его качественных и количественных характеристик. Функиионирование зависимости ранга источники разведыввательных сведений от его разведывательной ценности и отождествляемых с ними радиоэлектронной обстановкой реализуется нечеткой нейронной сетью. Результатом выполнения процедуры ранжирования является введение на множестве источников разведывательных сведений планируемых отночение порядке. Упорядочение Modern Information Technologies in the Sphere of Security and Defence № 1(37)/2020 ISSSN2311-7249(Print)/ISSSN2410-7336(Onime) 101 
множества источников разведьвательных сведений позволяет формализовать и решить задачу квазиоптимального распределения средств и сил разведки.

Ключевые слова: ранжирование, источники разведывательных сведений, объект разведки, планирования разведки, нечеткие множества, применение сил и средств разведки.

\title{
METHODS OF ORGANIZING RESOURCES SOURCES OF RADIO ELECTRONIC INTELLIGENCE IN ORGANIZATION AND EXERCISE
}

\author{
Serhii Hatsenko (Candidate of technical sciences) \\ Oleh Kostenko \\ Viktor Kuzmenko \\ Vasyl Mazurenko
}

\section{National Defence University of Ukraine named after Ivan Cherniakhovsky, Kyiv, Ukraine}

The article proposes a solution to the urgent scientific task of developing a scientific and methodological apparatus for ranking intelligence sources that characterize intelligence objects in assessing the operational situation and the electronic environment in the interests of intelligence planning. The rank of intelligence sources is calculated taking into account its qualitative and quantitative characteristics. The functioning of the dependence of the rank of sources of intelligence on its intelligence value and the radio-electronic environment that is associated with them is realized by a fuzzy neural network. The result of the ranking procedure is the introduction on a variety of sources of intelligence information of the planned relationship order. Streamlining the many sources of intelligence allows us to formalize and solve the problem of quasi-optimal distribution of intelligence assets and forces.

Key words: ranking, sources of intelligence, reconnaissance object, intelligence planning, fuzzy sets, the use of intelligence forces.

\section{References}

1. Gaczenko S. S. Metodika raczi 'onal'nogo rozpodi'lu rozvi`duval'noyi i’nformaczi`yi za vazhlivi'styu ta ki'l'ki'styu rozvi'duval'nikh oznak v umovakh neviznachenosti': Zbi 'rnik naukovikh pracz' NDI' GUR Mi 'ni sterstva oboroni Ukrayini, 2017. \# 43. S. 111-120. 2. Gaczenko S. S. I’nformaczi 'jna sistema oczi ’nyuvannya operativnoyi obstanovki $\mathrm{v}$ umovakh neviznachenosti : K.: NUOU, 2017. \# \# 1 (140), S. 157-165. 3. Shurenok V. A. Metodika oczi’nki kosmi 'chnoyi obstanovki na bazi nechi 'tkoyi logi 'ki: Zbi 'rnik naukovikh pracz' Vi js 'kovogo i'nstitutu Kivivs 'kogo naczi onal'nogo uni'versitetu i`meni Tarasa Shevchenka. 2003. S. 191-203. 4. Grebenyuk O. P. Zastosuvannya sistemno-kogni tivnogo anali zu dlya avtomatizaczi 'yi upravli 'nnya sistemoyu radi omoni toringu / O. P. Grebenyuk, M. A. Rogovecz', V. A. Shurenok // Vi`snik ZhDTU / Tekhni chni` nauki. - 2010. \# 1 (52). - S. 72 - 80. 5. Shurenok V.A., Dzyubchuk R.V., Rogovecz' M.A. I'nformaczi 'jna sistema pi`dtrimki prijnyattya ri’shennya oczi'nyuvannya radi'oelektronnoyi obstanovki na komandnikh punktakh chastin ta pi drozdi 'li ${ }^{\prime} v$ osoblivogo priznachennya $\mathrm{v}$ umovakh neviznachenosti' na osnovi konczepczi yi „m'yakikh obchislen'”. Trudi akademi 'yi. Kiviv: Naczi 'onal'na Akademi'ya oboroni Ukrayini. 2006, \# 71. s. 50-58. 6. Te’rano T., Asa i K.. Sugeno M. Prikladny’e nechetkie sistemy`. - M.: Mir,1993. -368 s. 7. Gill F.,
Myurrei U.. Rait M. Prakticheskaya optimizacziya: mer. s angl. - M.: Mir, 1985. 509 s. 8. Kruglov V.V.. Borisov V.V. Iskusstvenny`e neironny`e seti. Teoriya i praktika. - M Goryachaya liniya - Telekom, 2002. - 382 s. 9. Permyakov O. Yu. Teoreticheskie osnovy' obrabotki nechetkikh danny'kh v analiticheskikh zadachakh speczial'nogo matematicheskogo obespecheniya: Diss. na sois. uch. stepeni d. t. n. K.: 1995. 198 s. 10. Gaczenko S. S. Zujko V. V., Zotov S. V. Metodika viroblennya ta nadannya rekomendaczi $j \quad v$ umovakh neviznachenosti ta superechlivosti' rozvi`duval'noyi i’nformaczi`yi: Zbi`rnik naukovikh pracz' CzNDI OVT ZSU. 2016. \# 3 (62). S. 12 23. 11. Method of integral estimation of channel state in the multiantenna radio communication systems $\mathrm{S}$. Kalantaievska. H. Pievtsov, A. Kuvshynov, S. Hatsenko, A. Shyshatskyi, S. Yarosh, S. Zubrytskyi, R. Zhyvotovskyl, S. Petruk, V. Zulko Eastern-european journal of enterprise technologies. Vol. 5, No 9 (95) pp. 60-76, 2018: Information and controlling system. 12. Method of Immunity Minimization of the Free Platform ed Inertial Navigation System of Unmanned Aircrafts R. Bieliakov, S. Hatsenko, O. Fesenko, R. Zhyvotovskyi, S. Petruk, 2nd Ukraine Conference on Electrical and Computer Engineering Lviv, Ukraine, July 2-6, rr. 803-808, 2019. 